\title{
EFFECTS OF SPECIES-SPECIFIC PROBIOTIC ADDITION TO MILK REPLACER ON CALF HEALTH AND PERFORMANCE DURING THE FIRST MONTH OF LIFE*
}

\author{
Alessandro Agazzi ${ }^{1 *}$, Erica Tirloni ${ }^{1}$, Simone Stella ${ }^{1}$, Serena Maroccolo ${ }^{1}$, Barbara Ripamonti ${ }^{1}$, \\ Carla Bersani ${ }^{1}$, Jessica Michela Caputo ${ }^{1}$, Vittorio Dell'Orto ${ }^{1}$, Nicola Rota $^{2}$, Giovanni Savoini ${ }^{1}$ \\ ${ }^{1}$ Department of Health, Animal Science and Food Safety, \\ ${ }^{2}$ Department of Veterinary Science and Public Health, \\ University of Milan, Via Celoria 10, I-20133 Milan, Italy \\ •Corresponding author: alessandro.agazzi@unimi.it
}

\begin{abstract}
The aim of this study was to evaluate the effects of the administration of a species-specific probiotic (Lactobacillus animalis SB310, Lactobacillus paracasei subsp. paracasei SB137 and Bacillus coagulans SB117 in a 30:35:35 ratio, respectively; $1.8 \times 10^{10} \mathrm{CFU} / \mathrm{g}$ of powder) on gut microbial balance, immune response and growth performance of Holstein female calves during the first month of life. Twenty-two calves were divided into two experimental groups from 2 to 28 days of life: control (C), fed with milk replacer and concentrate as a basal diet, and treatment (T), fed C diet plus $1 \mathrm{~g} / \mathrm{calf} /$ day of probiotic powder for the first month of age. Faecal and blood samples were individually collected and analysed weekly. Individual faecal score was recorded daily and general health score was calculated at the end of the trial. Cell-mediated immune response was evaluated by skin test at 7 and 28 days of life. Milk replacer and concentrate intake were recorded daily, while body weight and biometrical parameters were recorded at $2,8,14,21$ and 28 days of life, thus average daily gain and feed conversion rate were calculated. During the first week of treatment, lower blood eosinophil percentage $(0.05 \%$ vs. $0.22 \% ; P \leq 0.01)$ was found in $T$ group, while basophils were higher in $\mathrm{T}$ than $\mathrm{C}$ group at the end of the trial $(0.21 \%$ vs. $0.16 \% ; \mathrm{P} \leq 0.05)$. Higher faecal lactic acid bacteria (LAB)/E. coli ratio on day 28 of life ( $3.73 \log$ CFU/g vs. $2.02 \log$ CFU/g; P $\leq 0.05)$ and lower incidence of diarrhoea were found in the treated group $(63.30 \% \mathrm{vs} .70 .71 \% ; \mathrm{P}=0.05)$. Body weight (48.92 kg vs. $46.92 \mathrm{~kg} ; \mathrm{P} \leq \mathbf{0 . 0 5})$, total concentrate intake (14.77 kg vs. $12.56 \mathrm{~kg}$ on dry matter basis; $P \leq 0.05)$, and heart girth $(81.16 \mathrm{~cm}$ vs. $78.49 \mathrm{~cm} ; \mathbf{P} \leq \mathbf{0 . 0 5})$ were significantly higher in $T$ group. The administration of the probiotic during the first month of life improved gut microbiota and increased the growth performance and some biometric parameters of calves.
\end{abstract}

Key words: calf, health status, growth performance, intestinal microbial balance, species-specific probiotic

*The present trial was funded through the Plan for Research and Development of the Lombardy Region (2007-2009), DG Agriculture, d.g.r. 8/3620, Italy (Project No. 1340 "Study and evaluation of a species-specific probiotic for veal calves" (BIOVAPRO)). 
Calf health is a critical factor linked to the economics of intensive breeding: health in the first weeks of life is strictly linked not only to the mortality rate, but also to the impact on morbidity with increased antibiotic and feed costs (Chaucheyras-Durand and Durand, 2010; Gaggìa et al., 2010).

In the first month of life, calves possess an extremely unstable intestinal microbiota (Lucàs et al., 2007) and are easily susceptible to the proliferation of pathogenic microorganisms that frequently lead to gastrointestinal diseases, particularly diarrhoea, with low digestion rates and reduced absorption of nutrients as a result (Signorini et al., 2012). Calf diarrhoea and intestinal diseases are often treated by antibiotics or other antimicrobial agents, but this could lead to serious and alarming consequences such as the development of antimicrobial resistance among the microbial population. In recent years, it was stated that the improvement of immune status and health of livestock by different dietary additives or compounds could be effective to prevent mass antibiotic treatments (Gaggìa et al., 2010; Savoini et al., 2010; Sun et al., 2010; Sun et al., 2011). It is well known that feeding calves with probiotics, especially lactic acid bacteria (LAB) (Corcionivoschi et al., 2010; Morrison et al., 2010; Riddel et al., 2010), improves gut health with a subsequent increase in digestion efficiency and thus better growth performance (Frizzo et al., 2010; Kawakami et al., 2010; Frizzo et al., 2011 a). In addition, the synergism in multispecies-multistrain probiotics seems to be more effective than monostrain products (Timmerman et al., 2005, 2004). In a previous work, we focused on the activity of isolated-lactic acid bacteria from veal calf faeces; thus it was possible to design a species-specific multistrain probiotic composed of Lactobacillus animalis SB310, Lactobacillus paracasei subsp. paracasei SB137 and Bacillus coagulans SB117 at an inclusion rate respectively of 30\%, $35 \%$, and $35 \%$ of the probiotic formulation that was successfully tested for in vitro antimicrobial activity towards different potentially pathogenic bacteria and multiresistant Escherichia coli (Ripamonti et al., 2009, 2011, 2013). This probiotic was then administered to calves from 15 days of life until 6 months of life with positive results on health status and growth, but no information on the effectiveness of the experimental compound has been collected during the early stages of life, when most of the gut-related diseases can occur (Frizzo et al., 2011 b). Providing better health status in the very first weeks of life could lead to subsequent increased growth performance in both male and female calves. Thus, the aim of this study was to evaluate the effects of the administration of the same probiotic, in 2-day-old calves until the first month of life, with particular interest on gut microbial balance, immune response and growth performance.

\section{Material and methods}

\section{Design of the experiment}

A total number of 22 Holstein female calves were randomly divided into 2 homogeneous groups on the basis of body weight from the second day of life until 28 days of age: control group (C), fed with a standard milk replacer/concentrate diet, and treated group $(\mathrm{T})$, fed with the same diet supplemented with $1 \mathrm{~g} / \mathrm{calf} /$ day of probiotic 
powder added to the morning milk feeding bucket (L. animalis - L. paracasei B. coagulans, with final concentration of $1.8 \times 10^{10} \mathrm{CFU} / \mathrm{g}$ in the powder). Each calf was placed in individual outdoor boxes $(2.00 \times 1.25 \mathrm{~m})$, with free access to water. Calves were fed individually twice a day $(7.00 \mathrm{am}-17.00 \mathrm{pm})$, with non-medicated milk replacer $(22.5 \%$ crude protein, $18 \%$ fat, $9.0 \%$ ashes, $1.75 \%$ lysine, $0.55 \%$ methionine and $0.50 \%$ cysteine on dry matter basis). The milk powder (130 g/l) was reconstituted in hot water $\left(65^{\circ} \mathrm{C}\right)$ and fed at a temperature of $39^{\circ} \mathrm{C}$ in the bucket. Initial amount of milk replacer was 4 1/calf/day, reaching $51 /$ calf/day at the end of the trial; refusals were determined for each feeding. Starting from the second day of life a commercial pelleted concentrate composed of wheat bran, soybean meal, and flaked corn $(20.28 \%$ crude protein, $4.38 \%$ crude fat, $30.01 \%$ NDF on dry matter basis) was offered ad libitum from a bucket. On days 2, 8, 14, 21 and 28 of life individual samples of blood and faeces were collected, while on day 8 and 28 skin test was performed on each calf. Individual faecal score (FS), incidence of diarrhoea and antibiotic treatments were recorded daily and general health score (GHS) was subsequently calculated. Moreover, on days 2, 8, 14, 21 and 28 of life body weight (BW) and biometric parameters were determined, and average daily gain (ADG) calculated. Individual daily milk replacer and concentrate intake was recorded and feed conversion rate (FCR) calculated on a weekly basis.

\section{Haematological parameters}

Blood samples from jugular vein were individually collected into $10 \mathrm{ml}$ lithium heparin vacuum tubes (Terumo Venosafe $10 \mathrm{ml}$ VF-109SHL, Terumo Europe L.V., Leuven, Belgium) at 2, 8, 14, 21, and 28 days of life. White blood cell count (WBC) and the content of basophils, neutrophils and eosinophils were assessed by a Hemat 8 device (SEAC, Calenzano, Florence, Italy). Haematocrit, red blood cell count, mean cell volume, haemoglobin, mean cell haemoglobin, mean cell haemoglobin concentration, platelets, platelet distribution width, mean platelet volume, percentage of large platelets, plateletcrit, neutrophils, red cell distribution width, blood lymphocyte and monocyte count were determined by an automated veterinary haematology analyser (Nihon Kohden, Cell Tac a, MEK 6108, Tokyo, Japan).

\section{Faecal and general health scores}

Individual faecal score was measured daily on a scale of 1 to 5 ( 1 = watery, $2=$ thin, custard like; $3=$ ideal condition, $4=$ stiff, $5=$ constipated, horse like; Zaaijer and Noordhuizen, 2003). General health score (GHS) was calculated using the formula suggested by Timmerman et al. (2005) and modified as follows: $28-(1 \times$ total number of diarrhoeic days $)-(2 \times$ number of individual therapeutic treatments for digestive diseases $)-(3 \times$ number of individual therapeutic treatments for respiratory diseases $)-(2 \times$ number of individual therapeutic treatments for infections other than digestive or respiratory $)-(2 \times$ number of antibiotic treatments on a herd basis $)$.

\section{Faecal collection and enumeration of LAB and Escherichia coli}

Individual faecal samples were collected on days 2, 8, 14, 21 and 28 of life by rectal stimulation, stored in vials $\left(4^{\circ} \mathrm{C}\right)$ with transport medium $\left(\right.$ Faecal ${ }^{\mathrm{TM}}$ enteric Plus, 
Oxoid, Basingstoke, UK), and analysed on the same day. Ten grams of each sample were diluted with $90 \mathrm{~mL}$ of Buffered Peptone Water (Oxoid, Basingstoke, UK) and homogenized in a Stomacher for $1 \mathrm{~min}$ (Seward Stomacher 400 blender Mixed Homogenizer, International PBI, Milano, Italy). Serial 10-fold dilutions were spread by sterile spatula onto MRS agar medium (Oxoid, Basingstoke, UK) as reported by Ripamonti et al. (2011) and TBX agar (ISO 16649-2) (Oxoid, Basingstoke, UK) for the enumeration of LAB and Escherichia coli, respectively. MRS agar plates were incubated in anaerobic jars (Anaerojar, Oxoid, Basingstoke, UK) with Anaerogen kit (Oxoid, Basingstoke, UK) at $37^{\circ} \mathrm{C}$ for $48 \mathrm{~h}$, while TBX agar plates were incubated aerobically at $44^{\circ} \mathrm{C}$ for $24 \mathrm{~h}$. After incubation, the agar plates were assessed for growth and typical colonies were counted. $\mathrm{LAB} / E$. coli ratio was calculated as the log difference between LAB and E. coli (Abu Tarboush, 1996).

\section{Skin test}

Cell-mediated immune response was evaluated to determine double skin thickness in response to phytohaemagglutinin injection (PHA, Sigma Chemicals, St. Louis, MO, USA) using the test procedure described by Agazzi et al. (2007) at 8 and 28 days after birth. Intradermal injection of $250 \mu \mathrm{g}$ PHA diluted in $0.1 \mathrm{ml}$ of sterile PBS (Sigma Chemicals, St. Louis, MO, USA) was performed on a top-part shaved area of right shoulder using an automatic syringe (Veterinaria Strumenti, Padova, PD, Italy). Sterile PBS $(0.1 \mathrm{ml})$ was injected into the corresponding area of left shoulder in order to check any skin response to PBS alone. Double skin thickness to both areas was measured with a constant tension calliper (Mitutoyo Italiana, Lainate, MI, Italy) before (time 0) and 24 hours after PHA injection. Values obtained at $24 \mathrm{~h}$ were considered the maximum PHA response (Lacetera et al., 1999).

\section{Growth performance}

Individual $\mathrm{BW}$ was recorded at 2, 8, 14, 21 and 28 days of age, by an electronic weighing system (model BF/E 1425E, Technosystem, Italy) and ADG calculated.

On the same days as for BW, biometric parameters such as heart girth, body length, withers height and hip width, were measured by a calibrated meter according to Hoffman (1997).

Milk replacer and concentrate intake were daily recorded by the difference between offered amounts and total daily refusals on a dry matter basis. Subsequently FCR was calculated using the sum of both milk replacer and concentrate dry matter intake on a weekly basis.

\section{Statistical analysis}

Haematological parameters, general health score, enumeration of LAB and E. coli, skin test and growth performance were analysed by a mixed procedure of SAS 9.2 (SAS INSTITUTE SAS Inc, NC, USA) for repeated measurements. The statistical model included the following main effects and interactions: treatment, day of treatment, and treatment by day of treatment. The animal was included in the model statement as the subject. 
Probability values $\mathrm{P}>0.05$ were considered non-significant, whereas $P$-value between 0.05 and 0.10 was considered as a trend. All data in the tables are presented as least square means \pm SEM:

$$
Y_{i j k}=\mu+T_{i}+D_{j}+A_{k}\left(T_{i}\right)+(T \times D)_{i j}+e_{i j k}
$$

where:

$\mu=$ general mean,

$T_{i}=$ effect of $i$ th treatment $(\mathrm{i}=1,2)$,

$D_{j}=$ effect of day of treatment $(\mathrm{j}=1,27)$,

$A_{k}\left(T_{i}\right)=$ effect of the animal nested in their group $(\mathrm{k}=1,22 ; \mathrm{i}=1,2)$,

$(T \times D)_{i j}=$ effect of the interaction between treatment and day of treatment,

$e_{i j k}=$ casual effect of each observation.

General health score, skin test, total milk replacer and concentrate intake, and FCR, were analysed by a General Linear Model procedure of SAS 9.2 (SAS INSTITUTE SAS Inc, NC, USA). Faecal scores below 3 were considered diarrhoeic, thus the total calf days below or over 3 were calculated and counts were analysed by a PROC FREQ of SAS with a chi-square option in order to estimate the incidence of diarrhoea in the two experimental groups.

\section{Results}

\section{Haematological parameters}

Blood count values were similar in the $\mathrm{C}$ and $\mathrm{T}$ for most of the parameters (Table $1)$, except for higher haematocrit $(\mathrm{P} \leq 0.05)$ and blood haemoglobin $(\mathrm{P} \leq 0.05)$ content at 8 days of life in T group. White blood cell count was within the physiological ranges, and no differences were observed in the two groups, except for lower eosinophil percentage in the first week of the trial $(\mathrm{P} \leq 0.01)$, and higher basophil percentage on day $28(\mathrm{P} \leq 0.05)$ in $\mathrm{T}$ group.

\section{Faecal and health scores, enumeration of faecal LAB and $E$. coli}

Diarrhoea frequency was significantly reduced in $\mathrm{T}$ compared to $\mathrm{C}$ animals during the trial $(P=0.05)$, while GHS was not influenced by the treatment $(T=19.54$ vs. $\mathrm{C}=18.90 ; \mathrm{P}>0.1)$. LAB counts obtained from faecal samples were stable for the whole trial and not significantly different in the two experimental groups, generally ranging between 7.5 and $8 \log \mathrm{CFU} / \mathrm{g}$. Decreasing $E$. coli faecal counts were found during the trial in $\mathrm{T}$ group while a slight increase in $\mathrm{C}$ group was observed starting from 14 days of experiment, but no significant differences were detected among the two experimental groups. $\mathrm{LAB} / E$. coli ratio showed significantly higher values in $\mathrm{T}$ group on day $28(\mathrm{P} \leq 0.05)$ (Figure 1$)$. 
Table 1. Haematological parameters in control $(\mathrm{C})$ and treated $(\mathrm{T})$ groups $(\mathrm{A}, \mathrm{B}-\mathrm{P}<0.01$; $\mathrm{a}, \mathrm{b}-\mathrm{P}<0.05)$

\begin{tabular}{|c|c|c|c|c|c|c|c|}
\hline \multirow{2}{*}{ Item } & \multirow{2}{*}{$\begin{array}{l}\text { Time } \\
\text { (Day) }\end{array}$} & \multicolumn{2}{|c|}{ Group } & \multicolumn{4}{|c|}{$\mathrm{P}$} \\
\hline & & $\mathrm{C}$ & $\mathrm{T}$ & SEM & G & $\mathrm{T}$ & $\mathrm{G}^{*} \mathrm{~T}$ \\
\hline 1 & 2 & 3 & 4 & 5 & 6 & 7 & 8 \\
\hline \multirow[t]{5}{*}{ Hct (\%) } & 2 & 23.79 & 27.08 & 1.46 & $<0.01$ & $<0.01$ & 0.97 \\
\hline & 8 & $22.17 \mathrm{~b}$ & $26.68 \mathrm{a}$ & & & & \\
\hline & 14 & 22.04 & 24.61 & & & & \\
\hline & 21 & 20.46 & 23.52 & & & & \\
\hline & 28 & 28.32 & 21.69 & & & & \\
\hline \multirow[t]{5}{*}{$\mathrm{Rbc}(106 / \mu \mathrm{l})$} & 2 & 6.33 & 7.00 & 0.41 & $<0.01$ & $<0.01$ & 0.973 \\
\hline & 8 & 6.12 & 7.07 & & & & \\
\hline & 14 & 6.09 & 6.54 & & & & \\
\hline & 21 & 5.47 & 6.25 & & & & \\
\hline & 28 & 4.81 & 5.76 & & & & \\
\hline \multirow[t]{5}{*}{ Mcv (fl) } & 2 & 37.67 & 38.78 & 0.59 & 0.05 & 0.07 & 0.36 \\
\hline & 8 & 36.23 & 37.84 & & & & \\
\hline & 14 & 36.34 & 37.61 & & & & \\
\hline & 21 & 37.62 & 37.89 & & & & \\
\hline & 28 & 38.50 & 37.97 & & & & \\
\hline \multirow[t]{5}{*}{$\operatorname{Hbg}(\%)$} & 2 & 8.80 & 9.93 & 4.65 & $<0.01$ & 0.74 & 0.93 \\
\hline & 8 & $8.60 b$ & $10.04 \mathrm{a}$ & & & & \\
\hline & 14 & 8.67 & 9.54 & & & & \\
\hline & 21 & 8.59 & 9.27 & & & & \\
\hline & 28 & 8.44 & 9.29 & & & & \\
\hline \multirow[t]{5}{*}{$\operatorname{Mch}(\%)$} & 2 & 14.14 & 14.41 & 0.74 & 0.71 & $<0.01$ & 0.73 \\
\hline & 8 & 14.10 & 14.49 & & & & \\
\hline & 14 & 14.27 & 14.80 & & & & \\
\hline & 21 & 16.04 & 15.38 & & & & \\
\hline & 28 & 18.06 & 16.84 & & & & \\
\hline \multirow[t]{5}{*}{ Mchc (\%) } & 2 & 37.49 & 37.24 & 1.58 & 0.25 & $<0.01$ & 0.93 \\
\hline & 8 & 38.99 & 38.26 & & & & \\
\hline & 14 & 39.60 & 39.26 & & & & \\
\hline & 21 & 42.47 & 40.51 & & & & \\
\hline & 28 & 46.62 & 44.13 & & & & \\
\hline \multirow[t]{5}{*}{ Plt $(103 / \mu l)$} & 2 & 606.64 & 543.18 & 59.58 & 0.49 & $<0.01$ & 0.80 \\
\hline & 8 & 758.33 & 823.45 & & & & \\
\hline & 14 & 702.09 & 743.70 & & & & \\
\hline & 21 & 647.18 & 677.20 & & & & \\
\hline & 28 & 519.73 & 576.50 & & & & \\
\hline \multirow[t]{5}{*}{ Pdw (fl) } & 2 & 72.40 & 75.60 & 2.74 & 0.18 & $<0.01$ & 0.94 \\
\hline & 8 & 69.85 & 74.36 & & & & \\
\hline & 14 & 66.82 & 67.12 & & & & \\
\hline & 21 & 65.90 & 67.55 & & & & \\
\hline & 28 & 66.00 & 67.83 & & & & \\
\hline
\end{tabular}


Table 1 - contd.

\begin{tabular}{|c|c|c|c|c|c|c|c|}
\hline 1 & 2 & 3 & 4 & 5 & 6 & 7 & 8 \\
\hline \multirow[t]{5}{*}{ Mpv (fl) } & 2 & 64.50 & 64.90 & 1.13 & 0.61 & $<0.01$ & 0.99 \\
\hline & 8 & 62.86 & 63.36 & & & & \\
\hline & 14 & 59.63 & 60.37 & & & & \\
\hline & 21 & 59.20 & 59.89 & & & & \\
\hline & 28 & 60.17 & 59.67 & & & & \\
\hline \multirow[t]{5}{*}{ Plcr (fl) } & 2 & 43.80 & 49.70 & 4.92 & 0.28 & $<0.01$ & 0.91 \\
\hline & 8 & 36.00 & 43.82 & & & & \\
\hline & 14 & 23.86 & 25.75 & & & & \\
\hline & 21 & 23.60 & 26.33 & & & & \\
\hline & 28 & 23.50 & 21.83 & & & & \\
\hline \multirow[t]{5}{*}{ Pct $(\%)$} & 2 & 39.10 & 35.50 & 4.63 & 0.56 & $<0.01$ & 0.85 \\
\hline & 8 & 49.57 & 52.18 & & & & \\
\hline & 14 & 42.27 & 47.50 & & & & \\
\hline & 21 & 36.50 & 39.33 & & & & \\
\hline & 28 & 34.33 & 37.16 & & & & \\
\hline \multirow[t]{5}{*}{ Rdw (fl) } & 2 & 274.64 & 271.45 & 6.50 & 0.92 & 0.08 & 0.81 \\
\hline & 8 & 284.11 & 285.55 & & & & \\
\hline & 14 & 294.00 & 284.90 & & & & \\
\hline & 21 & 285.64 & 290.20 & & & & \\
\hline & 28 & 277.27 & 281.60 & & & & \\
\hline \multirow[t]{5}{*}{ Wbc $(103 / \mu 1)$} & 2 & 8.66 & 9.95 & 0.89 & 0.96 & 0.94 & 0.67 \\
\hline & 8 & 8.98 & 9.73 & & & & \\
\hline & 14 & 9.37 & 8.99 & & & & \\
\hline & 21 & 9.02 & 8.39 & & & & \\
\hline & 28 & 9.42 & 8.53 & & & & \\
\hline \multirow[t]{5}{*}{ Monocytes (\%) } & 2 & 12.14 & 10.61 & 1.55 & 0.59 & $<0.01$ & 0.63 \\
\hline & 8 & 9.35 & 8.74 & & & & \\
\hline & 14 & 15.65 & 13.58 & & & & \\
\hline & 21 & 14.90 & 15.96 & & & & \\
\hline & 28 & 16.96 & 17.44 & & & & \\
\hline \multirow[t]{5}{*}{ Lymphocytes (\%) } & 2 & 19.01 & 22.45 & 4.12 & 0.15 & $<0.01$ & 0.99 \\
\hline & 8 & 22.28 & 26.90 & & & & \\
\hline & 14 & 31.10 & 33.00 & & & & \\
\hline & 21 & 34.87 & 37.12 & & & & \\
\hline & 28 & 38.28 & 40.88 & & & & \\
\hline \multirow[t]{5}{*}{ Basophils (\%) } & 2 & 0.13 & 0.16 & 0.02 & 0.37 & 0.07 & 0.29 \\
\hline & 8 & 0.13 & 0.14 & & & & \\
\hline & 14 & 0.16 & 0.14 & & & & \\
\hline & 21 & 0.16 & 0.16 & & & & \\
\hline & 28 & $0.16 \mathrm{~b}$ & $0.21 \mathrm{a}$ & & & & \\
\hline \multirow[t]{5}{*}{ Neutrophils (\%) } & 2 & 66.64 & 62.94 & 4.14 & 0.28 & $<0.01$ & 0.99 \\
\hline & 8 & 65.03 & 62.34 & & & & \\
\hline & 14 & 51.27 & 51.01 & & & & \\
\hline & 21 & 48.34 & 44.58 & & & & \\
\hline & 28 & 42.69 & 38.79 & & & & \\
\hline
\end{tabular}


Table 1 - contd.

\begin{tabular}{c|c|l|l|l|l|l|c}
\hline 1 & 2 & 3 & 4 & 5 & 6 & 7 & 8 \\
\hline Eosinophils (\%) & 2 & 0.10 & 0.13 & 0.03 & 0.70 & 0.76 & 0.02 \\
& 8 & $0.22 \mathrm{~A}$ & $0.05 \mathrm{~B}$ & & & & \\
& 14 & 0.04 & 0.10 & & & & \\
& 21 & 0.03 & 0.07 & & & & \\
& 28 & 0.06 & 0.07 & & & & \\
\hline
\end{tabular}

LAB

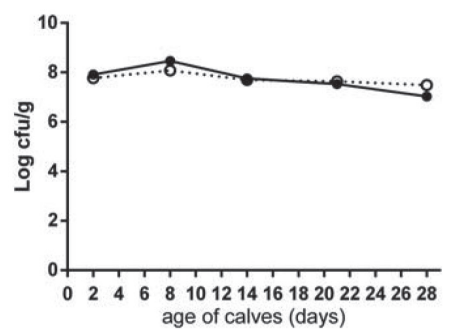

Escherichia coli

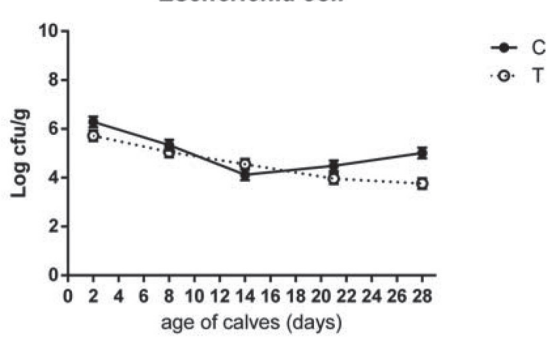

LAB/E. coli ratio

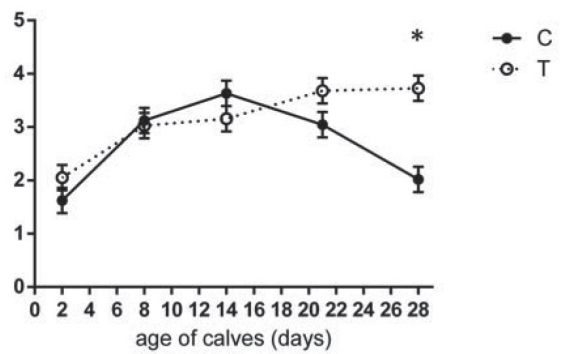

Figure 1. $\mathrm{LAB}, E$. coli and $\mathrm{LAB} /$ E. coli ratio in control $(\mathrm{C})$ and treated $(\mathrm{T})$ groups $(* \mathrm{P} \leq 0.05)$

\section{Skin test}

Skin thickness in PBS injection sites was not statistically different at $24 \mathrm{~h}$, thus no correction was performed on PHA-induced thickness. Both at 8 and at 28 days of life the skin thickness did not significantly increase with time up to 24 hours post PHA intradermal injection in $\mathrm{T}$ and $\mathrm{C}$, and no differences were found between the experimental groups (Table 2).

Table 2. Skin test in control (C) and treated (T) groups at $24 \mathrm{~h}$ post PHA intradermal injection

\begin{tabular}{c|c|c|c|c|c|c|c}
\hline \multirow{2}{*}{ Item } & \multirow{2}{*}{$\begin{array}{c}\text { Time } \\
\text { (Day) }\end{array}$} & \multicolumn{2}{|c|}{ Group } & \multicolumn{5}{c}{$\mathrm{P}$} \\
\cline { 3 - 8 } & $\mathrm{C}$ & $\mathrm{T}$ & $\mathrm{SEM}$ & $\mathrm{G}$ & $\mathrm{T}$ & $\mathrm{G} * \mathrm{~T}$ \\
\hline Skin thickness (mm) & 7 & 0.40 & 0.65 & 0.13 & 0.89 & 0.12 & 0.11 \\
& 28 & 0.48 & 0.19 & & & & \\
\hline
\end{tabular}




\section{Growth performance}

Initial body weight was not different in the two experimental groups (Table 3), while higher values were found in $\mathrm{T}$ than $\mathrm{C}$ at the end of the trial $(\mathrm{P}<0.05)$. Average daily gain, milk replacer intake and FCR were not influenced by the dietary treatment, while concentrate intake was significantly increased in $\mathrm{T}$ group $(\mathrm{P}<0.05)$. Biometrical parameters were similar in the two experimental groups during the trial, with the exception of increased mean heart girth in $\mathrm{T}$ compared to $\mathrm{C}$ group (81.16 cm vs. $78.49 \mathrm{~cm} ; \mathrm{P}<0.05)$.

Table 3. Growth performance in treated $(\mathrm{T})$ and control $(\mathrm{C})$ groups $(\mathrm{a}, \mathrm{b}-\mathrm{P} \leq 0.05)$

\begin{tabular}{|c|c|c|c|c|c|c|c|}
\hline \multirow{2}{*}{ Item } & \multirow{2}{*}{$\begin{array}{l}\text { Time } \\
\text { (Day) }\end{array}$} & \multicolumn{2}{|c|}{ Group } & \multicolumn{4}{|c|}{$\mathrm{P}$} \\
\hline & & $\mathrm{C}$ & $\mathrm{T}$ & SEM & G & $\mathrm{T}$ & $\mathrm{G}^{*} \mathrm{~T}$ \\
\hline \multicolumn{8}{|l|}{ Growth performance: } \\
\hline \multirow[t]{5}{*}{ body weight (kg) } & 2 & 39.40 & 39.92 & 0.56 & 0.12 & $<0.01$ & 0.31 \\
\hline & 8 & 41.49 & 40.86 & & & & \\
\hline & 14 & 41.84 & 43.06 & & & & \\
\hline & 21 & 43.80 & 44.72 & & & & \\
\hline & 28 & $46.92 \mathrm{~b}$ & $48.92 \mathrm{a}$ & & & & \\
\hline $\operatorname{ADG}(\mathrm{kg} / \mathrm{calf} / \mathrm{d})$ & $2-28$ & 0.29 & 0.37 & 0.06 & 0.54 & $\leq 0.01$ & 0.16 \\
\hline milk replacer $(\mathrm{kg} / \mathrm{DM} / \mathrm{calf})$ & $2-28$ & 12.18 & 12.12 & 0.73 & 0.83 & & \\
\hline concentrate (kg/DM/calf) & $2-28$ & $12.56 \mathrm{a}$ & $14.77 \mathrm{~b}$ & 0.68 & 0.03 & & \\
\hline FCR* & $2-28$ & 3.29 & 2.99 & 0.37 & 0.14 & & \\
\hline Diarrhoea frequency $(\%)$ & $2-28$ & 70.71 & 63.30 & & 0.05 & & \\
\hline \multicolumn{8}{|l|}{ Biometrical parameters: } \\
\hline \multirow[t]{5}{*}{ withers height $(\mathrm{cm})$} & 2 & 76.81 & 77.73 & 1.35 & 0.80 & $<0.01$ & 0.98 \\
\hline & 8 & 78.27 & 78.82 & & & & \\
\hline & 14 & 79.91 & 79.64 & & & & \\
\hline & 21 & 81.18 & 80.73 & & & & \\
\hline & 28 & 82.09 & 82.36 & & & & \\
\hline \multirow[t]{5}{*}{ heart girth $(\mathrm{cm})$} & 2 & 76.00 & 78.91 & 1.26 & 0.01 & $<0.01$ & 0.99 \\
\hline & 8 & 77.18 & 79.91 & & & & \\
\hline & 14 & 78.18 & 80.73 & & & & \\
\hline & 21 & 79.09 & 82.36 & & & & \\
\hline & 28 & 82.00 & 83.91 & & & & \\
\hline \multirow[t]{5}{*}{ hips width (cm) } & 2 & 20.91 & 22.00 & 0.58 & 0.05 & $<0.01$ & 0.87 \\
\hline & 8 & 21.64 & 22.55 & & & & \\
\hline & 14 & 22.36 & 23.45 & & & & \\
\hline & 21 & 23.45 & 23.82 & & & & \\
\hline & 28 & 24.09 & 24.27 & & & & \\
\hline \multirow[t]{5}{*}{ body length $(\mathrm{cm})$} & 2 & 60.00 & 61.27 & 1.51 & 0.78 & $<0.01$ & 0.92 \\
\hline & 8 & 61.54 & 61.82 & & & & \\
\hline & 14 & 63.27 & 62.54 & & & & \\
\hline & 21 & 64.73 & 63.82 & & & & \\
\hline & 28 & 66.54 & 65.27 & & & & \\
\hline
\end{tabular}

*FCR was calculated using the sum of both milk replacer and concentrate dry matter intake. 


\section{Discussion}

The results of this study indicate that the administration of a species-specific probiotic to a calf in the first month of life can lead to improved microbiota balance in the gut and increased body weight.

A variety of different probiotics has been proposed to improve growth performance, and several studies showed that dietary supplementation of LAB is able to improve growth performance in different animal species. The mechanism of action of probiotics is still debated, but generally, they are thought to function by maintaining the presence of beneficial microorganisms in the gut by the competitive exclusion of pathogenic bacteria adherence (Corcionivoschi et al., 2010; Morrison et al., 2010; Riddel et al., 2010). In this way probiotics can influence the intestinal microbiota as well as host health, also lowering the $\mathrm{pH}$ through acid fermentation, increasing nutrient utilization, producing bacteriocins and stimulating the immune system (Salim et al., 2013). Better performance has been reported since the use of a mixture of microorganisms with different species rather than a single microbial species or strain (Mead and Impey, 1986; Stavric et al., 1991). This improved efficacy of multistrain probiotic seems to be related to the better capability of colonizing the gastrointestinal tract than single-strain compounds, associated with a synergic activity due to the combination of different mechanisms of action, although many factors seem to influence the results obtained, such as the strain, the applied dosage, the duration of the treatment and the stage of rearing (Timmerman et al., 2004; Soto et al., 2010).

Lactobacillus, Bifidobacterium, Enterococcus and Saccharomyces are the most used probiotic genera in animals (Gaggìa et al., 2010). In addition, Bacillus spp., belonging to the spore-forming lactic acid bacteria (SFLAB) group, has been recently considered for probiotic functions (Suzuki and Yamasato, 1994; Chaucheyras-Durand and Durand, 2010). Lactobacillus spp. and Bifidobacterium spp. constitute a major component of the intestinal microflora of most animals (Endo et al., 2010) and are widely recognized for their beneficial effects, including maintaining the appropriate balance of microbiota, counteracting pathogenic bacteria colonization and improving the host mucosal immunity (Gaggìa et al., 2010), with minor variations on blood.

During the present trial haematological profile of veal calves followed the physiological trend generally observed for the first phases of life. The decreasing haematocrit and blood haemoglobin content observed can be considered a physiological trend from birth until the first weeks of life of young calves, probably due to the diet composition (Mohri et al., 2007). A slight lymphopaenia, associated with monocytosis and neutrophilia was revealed for the whole experimental period in both groups, but similar values can be usually detected in very young animals, and they do not represent a pathological condition (Mohri et al., 2007). In the present study haemoglobin levels and eosinophil percentage were significantly higher in $\mathrm{T}$ group at 8 days of life, while basophil percentage decreased at the end of the trial; these effects were observed also in other studies, but literature data are inconsistent and this item should be further investigated (Fleige et al., 2008; Matsumoto et al., 2009; Kim et al., 2011). 
Gut microbial balance is one of the most important factors to provide a good health status in young animals, particularly calves, where the immature immune system is prone to debilitating diarrhoea and respiratory diseases (Tsuruta et al., 2009). A growing number of studies in farm animals has reported that probiotic administration increases the number of beneficial bacteria and decreases the load of pathogens (Lalles et al., 2007; Gaggìa et al., 2010; Corcionivoschi et al., 2010), thus positively affecting the protective potential of animal gut with a lower incidence of intestinal and respiratory diseases. This is particularly important in intensive rearing systems of calves where the possibility of acquiring natural, autochthonous microbiota is strongly diminished, thus weakening the enteric bacteria balance (Frizzo et al., 2010). Feeding probiotics to suckling calves has been shown to improve digestion with beneficial repercussions on gut health, especially those related to the rate, severity and length of diarrhoeal episodes and even respiratory problems (Timmerman et al., 2005).

Oral administration of LAB-based probiotics has been already recognized as a promoter of intestinal microbial balance and growth performance (LeJeune and Wetzel, 2007; Al-Saiady, 2010; Nagashima et al., 2010) by the transient proliferation in the digestive tract and the development of a microbial defence against the growth of pathogenic bacteria. Lactic acid bacteria are recognized to be effective against Escherichia coli and Salmonella spp. that can be considered microbiological indicators of gut health. In fact it is widely recognized that healthy calves show higher Lactobacilli/coliform ratio than calves suffering from diarrhoea (Abu-Tarboush et al., 1996; Frizzo et al., 2010). Our study showed higher LAB/E. coli ratio in T group, suggesting a favourable equilibrium in the microbiota, especially during the last days of the trial in agreement with Timmerman et al. (2005), Stella et al. (2007) in goats, and Frizzo et al. (2011 a) in calves. The improved gut health status in our study was confirmed by the lower frequency of diarrhoea in T group in agreement with Kawakami et al. (2010).

The probiotic activity of our strains could be due to different mechanisms: L. animalis and L. paracasei subsp. paracasei have already shown an acidification capability due to the production of organic acids (acetic and lactic acid) (Ripamonti et al., 2011). B. coagulans couples the production of lactic acid and of two thermostable bacteriocins: coagulin, which showed a bactericidal and bacteriolytic action against different Gram positive bacteria, without inhibitory effects on lactobacilli (Hyronimus et al., 1998; Le Marrec et al., 2000) and a new bacteriocin with antimicrobial activity against Gram positive, Gram negative bacteria and fungi (Abada et al., 2008). Moreover, the spores of B. coagulans could cause immuno-stimulation through their contact with gut-associated lymphoid tissue (GALT), as observed for other Bacillus species (Huang et al., 2008; Ripamonti and Stella, 2009).

Skin test has been already performed in different species (Agazzi et al., 2004, 2007; Lacetera et al., 1999), but until now, very few trials were conducted on calves supplemented with probiotic in the first month of life. In our trial no differences in skin thickness were observed between the groups both at 8 or 28 days of life, in agreement with Roodposhti and Dabiri (2012) who found no variations, but at 60 days of life. The absence of statistical evidences in skin test during the first weeks 
of life has been observed also by Masucci et al. (2011) in young buffalo calves, evidencing the presence of a positive response only during later age (11 weeks).

Thus the lack of efficacy of our probiotic compound on immune response, as also outlined by the white blood cell count, seems almost related to the duration of treatment applied.

Most of the times the positive results of dietary probiotics on growth performance in the different animal species are thought to be an indirect effect of increased microbiota balance in the gut with a consequent lower prevalence of pathogens and higher nutrient utilization (Timmermann et al., 2004).

Accordingly, in the present trial the improvement of $\mathrm{LAB} / E$. coli ratio and FS as indices of health status of the calves could explain the higher final BW detected in probiotic-fed group as reported by several authors (Bakr et al., 2009; Hasunuma et al., 2011). In fact it is well known that many factors affecting the growth rate are caused by abnormal nutrient digestion and absorption (Davis and Drackley, 2002). Total calf concentrate intake was higher in treated group, which is in agreement with some other authors (Timmerman et al., 2005; Kawakami et al., 2010): this effect is particularly important as the dry matter intake in early stage of life is necessary to assure the proper growth of forestomachs, although literature reports inconsistent results (Abe et al., 1995; Bakshi et al., 2006). Finally, the administration of our species-specific multistrain probiotic showed to improve intestinal balance and reduce the incidence of enteric problems, although a direct effect on cell-mediated immune response was not observed. Further studies must be conducted on immune response variations in neonatal calves, also considering different stress conditions.

\section{References}

$\mathrm{A} \mathrm{b}$ a d a E.A. (2008). Isolation and characterization of an antimicrobial compound from Bacillus coagulans. Anim. Cells Syst., 12: 41-46.

A be F.N., Ishibashi X., Shima mura S. (1995). Effect of administration of bifidobacteria and lactic acid bacteria to newborn calves and piglets. J. Dairy Sci., 78: 2838-2846.

A b u - T a r b o u s h H.M., A l - S a i a d y M.Y., E 1 - D in A.H.K. (1996). Evaluation of diet containing Lactobacilli on performance, fecal coliform, and Lactobacilli of young dairy calves. Anim. Feed Sci. Tech., 57: 39-49.

Agazzi A., Cattane o D., De 11' Orto V., Moroni P., Bonizzi L., Pasotto D., Savoin i G. (2004). Effect of administration of fish oil on aspects of cell-mediated immune response in periparturient dairy goats. Small Ruminant Res., 55: 77-83.

A gazzi A., Cigalino G., Manc in G., S a vo in i G., Dell' Orto V. (2007). Effects of dietary humates on growth and an aspect of cell-mediated immune response in newborn kids. Small Ruminant Res., 72: 242-245.

A 1 - S a i a d y M.Y. (2010). Effect of probiotic bacteria on immunoglobulin G concentration and other blood components of newborn calves. J. Anim. Vet. Adv., 9: 604-609.

Bakhshi N., Ghorbani G.R., Rahmani H.R., S a mi e A. (2006). Effect of probiotic and milk feeding frequency on performance of dairy Holstein calves. Int. J. Dairy Sci., 1, 2: 113-119.

B a k r H.A., S a i d E.M., E 1 - Ta w a b A., H a s s a n M.S. (2009). The impact of probiotic (Biovet) on some clinical, hematological and biochemical parameters in buffalo-calves. Vet. Med. J., 19: 1-10.

Ch a u cheyras - D ur and F., D u rand H. (2010). Probiotics in animal nutrition and health. Beneficial Microbes. Wageningen Academy Publishers, 1, 1: 3-9. 
Corcionivoschi N., Drinceanu D., Pop I., St ack M., Stef D., Julean L. (2010). The effect of probiotics on animal health. Anim. Sci. Biotechnol., 43: 35-41.

D a v i s C.L., D r a c k le y J.K. (2002). Desarrollo, nutricion y manejo del ternero joven. Intermedica, Buenos Aires.

En d o A., F u t a g a w a - En d o Y., D i c k s L.M.T. (2010). Diversity of Lactobacillus and Bifidobacterium in feces of herbivores, omnivores and carnivores. Anaerobe, 16: 590-596.

Fleige S., PreiB inger H.H.D., M e yer Pfaffl M.W. (2008). The immunomodulatory effect of lactulose on Enterococcus faecium fed preruminant calves. J. Anim. Sci., 87: 1731-1738.

Frizzo L.S., S oto L.P., Zbrun M.V., B ertozzi E., S equeira G., Armesto R.R., Ros m in i M.R. (2010). Lactic acid bacteria to improve growth performance in young calves fed milk replacer and spray-dried whey powder. Anim. Feed Sci. Tech., 157: 159-167.

Frizzo L.S., S o to L.P., B ertozzi E., Zbrun M.V., S ignorin i M.L., S e que ir a G., Rodriguez R., Armesto R.R., R os mini M.R. (2011 a). Intestinal populations of Lactobacilli and Coliforms after in vivo Salmonella dublin challenge and their relationship with microbial translocation in calves supplemented with lactic acid bacteria and lactose. Anim. Feed Sci. Tech., 170: 12-20.

Frizzo L.S., Z b r u n M.V., S o t o L.P., S i g n or in i M.L. (2011 b). Effects of probiotics on growth performance in young calves: A meta-analysis of randomized controlled trials. Anim. Feed Sci. Tech., 169: 147-156.

G a g g ì a F., Matta relli P., B i avati B. (2010). Probiotics and prebiotics in animal feeding for safe food production. Int. J. Food Microbiol., 141: S15-S28.

Hasunuma T.K., Kawashima H., Nakayama H., Murakami T., Kanagawa H., Is hi i T., Akiy a ma K., Yas uda K., Terada F., Ku shibiki S. (2011). Effect of cellooligosaccharide or synbiotic feeding on growth performance, fecal condition and hormone concentrations in Holstein calves. Anim. Sci. J., 82: 543-548.

H o ffm a n P.C. (1997). Optimum body size of Holstein replacement heifers. J. Anim. Sci., 75: 836-845.

Huang J.M., L a Ragi on e R.M., N un ez A., Cutt ing S.M. (2008). Immunostimulatory activity of Bacillus spores. FEMS Immunol. Med. Mic., 53: 195-203.

Hyronimus B., Le Marrec C., Urdaci M.C. (1998). Coagulin, a bacteriocin-like inhibitory substance produced by Bacillus coagulans I4. J. Appl. Microbiol., 85: 42-50.

Kaw a k a mi S.I., Y a ma d a Y., N a k a n is h i N., C a i Y. (2010). Feeding of lactic acid bacteria and yeast on growth and diarrhea of Holstein calves. J. Anim. Vet. Adv., 9: 1112-1114.

K i m M.K., L e e H.G., P a rk J.A., Kang S.K., Cho i Y.J. (2011). Effect of feeding direct-fed microbial as an alternative to antibiotics for the prophylaxis of calf diarrhea in Holstein calves. Asian. Austral. J. Anim., 23: 643-649.

Lacetera N., Bernabucci U., Ronchi B., Nardone A. (1999). The effects of injectable sodium selenite on immune function and milk production in Sardinian sheep receiving adequate dietary selenium. Vet. Res., 30: 363-370.

L a 11 e s J.P., B o s i P., S m idt H., S t o k e s C.R. (2007). Nutritional management of gut health in pigs around weaning. Proc. Nutr. Soc., 66: 260-268.

L e J e u n e J.T., We tze 1 A.N. (2007). Preharvest control of Escherichia coli O157 in cattle. J. Anim. Sci., 85: 73-80.

Le Marrec C., Hyronimus B., Bressollier P., Verneuil B., Urdaci M.C. (2000). Biochemical and genetic characterization of coagulin, a new antilisterial bacteriocin in the pediocin family of bacteriocins, produced by Bacillus coagulans I4. Appl. Environ. Microbiol., 66: 5213-5220.

Lucas A.S., Swecker W.S., Lindsay D.S., Scaglia G., Elvinger F.C., Zajac A.M. (2007). The effect of weaning method on coccidial infections in beef calves. Vet. Parasitol., 145: $228-233$.

Masucci F., Ros a G.D., Gras s o F., N a politano F., Es pos ito G., Francia A.D. (2011). Performance and immune response of buffalo calves supplemented with probiotic. Livest. Sci., 137: 24-30.

Matsumoto D., Takagi M., Hasunuma H., Fushimi Y., Ohtani M., Sato T., Okamoto K., Shahada F., Tanaka T., Deguchi E. (2009). Effects of oral administration of difructose anhydride III on selected health and blood parameters of group-housed Japanese Black calves during the preweaning period. Asian-Aust. J. Anim., 22: 1640-1647. 
M e a d G.C., I m p e y C.S. (1986). Current progress in reducing Salmonella colonization of poultry by 'competitive exclusion'. J. Appl. Bacteriol. Symp. (Suppl. 61): 67-75.

Mohri M., Sharifi K., Eidi S. (2007). Hematology and serum biochemistry of Holstein milk calves: age related changes and comparison with blood composition in adults. Res. Vet. Sci., 83: 30-39.

Morris on S.J., Daw s on S., Cars on A.F. (2010). The effects of mannan oligosaccharide and Streptococcus faecium addition to milk replacer on calf health and performance. Livest. Sci., 131: 292-296.

Naga sh ima K., Yas ok aw a D., A be K., Nakagawa R., Kit a mu ra T., Mi ura T., Ko ga w a S. (2010). Effect of a Lactobacillus species on incidence of diarrhea in calves and change of the microflora associated with growth. Biosci. Microflora., 29, 2: 97-110.

Ridde 11 J.B., Galle gos A.J., Harmon D.L., M c Le od K.R. (2010). Addition of a Bacillus based probiotic to the diet of preruminant calves: influence on growth, health, and blood parameters. Int. J. Appl. Res. Vet. M., 8: 78-85.

Ripamonti B., Agazzi A., Baldi A., Balzaretti C., Bersani C., Pirani S., Rebuc c i R., S a v o in i G., S t e 11 a S., S t e n i c o A., D o m e n e g h in i C. (2009). Administration of Bacillus coagulans in calves: recovery from fecal samples and evaluation of functional aspects of spores. Vet. Res. Commun., 33: 991-1001.

R i pa monti B., S te 11 a S. (2009). Probiotici sporigeni per l'alimentazione animale. Large Animal Review, 15: 7-12.

Ripamonti B., Agazzi A., Bersani C., De Dea P., Pecorini C., Pirani S., Rebuc ci R., Savoini G., Stella S., Stenico A., Tirloni E., Domeneghini C. (2011). Screening of species-specific lactic acid bacteria for veal calves multi-strain probiotic adjuncts. Anaerobe., 17: 97-105.

Ripamonti B., Tirloni E., Stella S., Bersani C., Agazzi A., Maroccolo S., Savoi n i G. (2013). Effects of a species-specific probiotic formulation on multiresistant Escherichia coli isolates from the gut of veal calves. Czech J. Anim. Sci., 5: 201-207.

R o o d p o s h t i P.M., D a b i r i N. (2012). Effects of probiotic and prebiotic on average daily gain, fecal shedding of Escherichia coli, and immune system status in newborn female calves. Asian. Austral. J. Anim., 25, 9: 1255-1261.

S a 1 i m H.M., K a n g H.K., A k te r N., K i m D.W., K i m J.H., K i m M.J., N a J.C., J ong H.B., C h o i H.C., S u h O.S., K i m W.K. (2013). Supplementation of direct-fed microbials as an alternative to antibiotic on growth performance, immune response, cecal microbial population, and ileal morphology of broiler chickens. Poultry Sci., 92: 2084-2090.

Savoini G., Agazzi A., Invernizzi G., Cattaneo D., Pinotti L., Baldi A. (2010). Polyunsaturated fatty acids and choline in dairy goats nutrition: Production and health benefits. Small Ruminant Res., 88: 135-144.

Signorini M.L., S oto L.P., Zbrun M.V., S equeira G.J., Rosmini M.R., Frizzo L.S. (2012). Impact of probiotic administration on the health and fecal microbiota of young calves: a meta-analysis of randomized controlled trials of lactic acid bacteria. Res. Vet. Sci., 93: 250-258.

Soto L.P., Frizzo L.S., Bertozzi E., Avataneo E., Sequeira G.J., Rosmini M.R. (2010). Molecular microbial analysis of Lactobacillus strains isolated from the gut of calves for potential probiotic use. Vet. Med. Intern., pp. 1-8.

S t a vri c S., G l e e s o n T.M., B l a n c h f i e ld B. (1991). Efficacy of undefined and defined bacterial treatment in competitive exclusion of Salmonella from chicks. In: Colonization Control of Human Bacteria Enteropathogens in Poultry. L. C. Blankenship, ed. Academic Press Inc., New York, NY, pp. 323-330.

Stella A.V., Paratte R., Valnegri L., Cigalino G., Soncini G., Chevaux E., D e 11 ' O r t o V., S a v o in i G. (2007). Effect of administration of live Saccharomyces cerevisiae on milk production, milk composition, blood metabolites and fecal flora in early lactating dairy goats. Small Ruminant Res., 67: 7-13.

S un P., Wang J.Q., Z hang H.T. (2010). Effects of Bacillus subtilis natto on performance and immune function of preweaning calves. J. Dairy Sci., 93: 5851-5855.

S u n P., Wang J.Q., Z h a n g H.T. (2011). Effects of supplementation of Bacillus subtilis natto Na and N1 strains on rumen development in dairy calves. Anim. Feed Sci. Tech., 164: 154-160. 
Suzuki T., Yamas ato K. (1994). Phylogeny of spore-forming lactic acid bacteria based on 16S rRNA gene sequences. FEMS Microbiol. Lett., 115: 13-18.

Timmer man H.M., Kon ing C.J.M., Muld e r L., R o mbouts F.M., B e yne n A.C. (2004). Monostrain, multistrain and multispecies probiotic - a comparison of functionality and efficacy. Int. J. Food Microbiol., 96: 219-233.

Timmerman H.M., Mulder L., Everts H., Van Espen D.C., Van der Wal E., Klaas s en G., Rouwers S.M.G., Hartemink R., Rombouts F.M., B eynen A.C. (2005). Health and growth of veal calves fed milk replacers with or without probiotics. J. Dairy Sci., 88: $2154-2165$.

Tsuruta T., In oue R., Tsukahara T., M atsubara N., H a mas aki M., U shida K. (2009). A cell preparation of Enterococcus fecalis strain EC-12 stimulates the luminal immunoglobulin A secretion in juvenile calves. Anim. Sci. J., 80: 206-211.

$\mathrm{Z}$ a a ij er D., N o ord hu ize n J.P.T.M. (2003). A novel scoring system for monitoring the relationship between nutritional efficiency and fertility in dairy cows. Irish Vet. J., 56: 145-151.

Accepted for printing 7 X 2013 